\title{
A DOCÊNCIA NA EDUCAÇÃO INFANTIL DA REDE PÚBLICA MUNICIPAL DO RIO DE JANEIRO ATRAVESSADA PELOS MATERIAIS DIDÁTICOS ESTRUTURADOS
}

\author{
Cátia Cirlene G Oliveira \\ Secretaria Municipal de Educação/ Rio de Janeiro - SME-RJ, Brasil
}

\begin{abstract}
Resumo
A disponibilização de diferentes materiais didáticos para os professores que atuam na etapa da Educação Infantil, tanto em nível federal, como o Programa Nacional do Livro e do Material Didático (PNLD), quanto em nível local, pelas redes de ensino, têm se configurado como uma das principais políticas de currículo, que tem se justificado pela necessidade de orientar e treinar os professores, principalmente do segmento pré-escola, para atuarem na perspectiva da preparação das crianças para a alfabetização. Este artigo relata a experiência da rede pública municipal do Rio de Janeiro que, neste ano de 2021, diante do cenário de suspensão de aulas presenciais pela necessidade do afastamento social devido à pandemia da COVID-19, mas com a necessidade de manter, principalmente, o vínculo entre as escolas, as famílias e as crianças da etapa da Educação Infantil, promoveu uma mudança no formato de seus cadernos pedagógicos - material didático destinado ao uso pelas crianças - revelando que as interpretações para uma política e a sua finalidade podem ser alteradas pelas contingências, promovendo novas significações e novos usos para as políticas.
\end{abstract}

Palavras-chave: Políticas de Currículo; Teoria do Discurso; Educação Infantil; Materiais Estruturados para a Educação Infantil.

\begin{abstract}
The availability of different didactic materials for teachers who work in the Early Childhood Education stage, both at the federal level, such as the National Book and Didactic Material Program (PNLD), and at the local level, through educational networks, has been configured as one of the main curriculum policies, which has been justified by the need to guide and train teachers, especially in the pre-school segment, to act from the perspective of preparing children for literacy. This article reports the experience of the municipal public network in Rio de Janeiro that, in this year of 2021, faced with the scenario of suspension of in-person classes due to the need for social withdrawal due to the COVID-19 pandemic, but with the need to maintain, mainly, the link between schools, families and children in the Early Childhood Education stage promoted a change in the format of their educational material - teaching material intended for use by children - revealing that the interpretations for a policy and its purpose can be changed by contingencies, promoting new meanings and new uses for policies.
\end{abstract}

Keywords: Curriculum Policies; Discourse Theory; Child education; Structured Materials for Early Childhood Education. 


\section{Introdução}

Algumas discussões relacionadas à Educação Básica - EB e, especialmente, à Educação Infantil - EI têm ganhado relevância no cenário educacional atual. Em destaque, as políticas curriculares, desde que esta se tornou a primeira etapa da Educação Básica com a promulgação Lei de Diretrizes e Bases da Educação Nacional - LDB (Lei nº 9394/96) e dentre essas a produção de material didático para esta etapa e as políticas de formação de professores.

Ainda que os textos políticos pós LDB busquem superar as concepções de EI como etapa preparatória e/ou assistencialista, defendendo que sua finalidade está centrada no desenvolvimento e na aprendizagem da criança em todos os seus aspectos e buscando fixar sentidos de currículo que se aproximem mais das necessidades e especificidades da criança pequena, desvinculados da ideia de conteúdos a ensinar, a adoção de materiais didáticos, na forma de sistemas apostilados, tem se afirmado como uma das principais políticas de currículo e de formação de docentes na atualidade.

Compreendemos que a adoção dos sistemas apostilados é uma política curricular que vem encontrando espaço na Educação Infantil, sustentada pela necessidade de elevação dos índices de "qualidade" da educação pública (NASCIMENTO, 2012) e por uma suposta "precariedade da formação inicial" dos professores que atuam nesse segmento (KRAMER, 2006; KISHIMOTO, 2009) ou, ainda, pelas concepções de ensino-aprendizagemdesenvolvimento que estruturam as práticas pedagógicas nessa etapa. Esses são fatores que corroboram com a aceitação/disseminação da política.

Na Secretaria Municipal de Educação do Rio de Janeiro - SME/RJ, a utilização dos referidos cadernos vem sendo justificada pela necessidade de se reconhecer a dimensão pedagógica da pré-escola e a importância de que a alfabetização das crianças não seja relegada somente ao EF. Tal necessidade foi recentemente reforçada quando, em 2013, a Lei n 12.796 , deu nova redação ao artigo 6º da LDB 9394/96: "É dever dos pais ou responsáveis efetuar a matrícula das crianças na educação básica a partir dos 4 (quatro) anos de idade".

Esse era um ponto de debate entre educadores quando o EF foi ampliado para nove anos, incorporando crianças a partir dos seis anos de idade. Cabe ressaltar que na rede pública do município do Rio de Janeiro, o atendimento no segmento pré-escola encontra-se consolidado e praticamente universalizado, de modo que a referida lei não representa um grande desafio seja no que tange à expansão do número de vagas ou no que tange à estruturação da proposta pedagógica para esse segmento.

Há diferentes discursos já constituídos de que as atuais políticas apresentam-se como caminhos para superar as desigualdades sociais e para alcançar a democracia e de que elas são o caminho para o desenvolvimento da nação por meio da produtividade. No entanto, corremos o risco de estarmos trilhando o caminho inverso, ou seja, reafirmando as desigualdades e, até mesmo, diminuindo a nossa possível produtividade, ao formar cidadãos pouco críticos e criativos.

A produção de materiais didáticos na forma de livros e/ou apostilas para a EI (e demais etapas) encontra-se no cerne desses discursos, uma vez que incorpora, nesta etapa, um 
modelo de escolarização já consolidado nas etapas posteriores e vem se apresentando como "a saída possível" para a superação das dificuldades enfrentadas no que tange ao sucesso escolar das crianças.

Com referência na Teoria do Discurso - TD (LACLAU e MOUFFE, 2014), compreendemos que o discurso é tomado enquanto um complexo de elementos dados a partir de um conjunto de relações possível pela polissemia dos significados; como produto de disputas e articulações políticas contingentes; como o terreno primário no qual a realidade se constitui; um discurso se constitui e é reconhecido na sua articulação com outros significados já existentes.

Um discurso surge, também, como representativo de demandas heterogêneas que, a partir de um conjunto de relações se hegemoniza em torno de um mesmo significado, que deixa de ser literal e assume o status de metáfora, o que permite que diferentes demandas, de diferentes sujeitos, se tornem, ainda que provisoriamente, equivalentes e hegemônicas.

Uma categoria a se destacar na TD é o antagonismo, compreendido não como uma luta entre identidades prontas construídas antes da própria relação antagônica, mas como possibilidade para a formação de identidades. O antagonismo, nessa perspectiva, revela a precariedade e a contingência de qualquer identidade, uma vez que esta está sempre ameaçada por algo exterior a ela e, por esse exterior, também se constitui, pois ele pode revelar uma "falta": "eu sou o que o outro não é".

\section{Sentidos de currículo nos textos políticos pós LDB 9397/96}

Podemos considerar que o uso de materiais estruturados, na forma de apostilados, se constitui como um forte elemento que pretende regular a prática docente, de modo que essa regulação determine os ritos pedagógicos que os professores realizam no cotidiano da EI.

Embora seja considerável a influência que esses materiais exercem, a sua pretensão de fixar de forma permanente os seus sentidos (os seus discursos) é, de antemão, falida e isso é bom! Tanto as Diretrizes Curriculares Nacionais para a Educação Infantil - DCNEI (Resolução CNE/CP n 5 de 17 de dezembro de 2009) como a Base Nacional Comum Curricular - BNCC (Resolução CNE/CP No 2, DE 22 de dezembro de 2017) são fruto de articulações políticas e disputas por significação. Buscam difundir os conceitos de infância, de criança e de aprendizagem (entre outros) oriundos das recentes pesquisas de campos como o da psicologia, da sociologia e da neurociência, por exemplo. Ancorados nesses conceitos pretendem definir quais são os fins da EI brasileira e intentam orientar a adoção de novas práticas pedagógicas cotidianas mais condizentes a esses, antagonizando-se aos modelos assistencialista e/ou preparatório que marcam a história da EI brasileira.

No entanto, podemos observar, nos dois documentos citados, significações distintas da própria EI e do currículo desta etapa, o que revela a precariedade e a contingência dessas significações. Enquanto as DCNEI (2009, p.12) definem a Educação Infantil com "a primeira etapa da educação básica oferecida em creches e pré-escolas (...) que educam e cuidam de crianças de 0 a 5 anos de idade (...)", revelando uma concepção de criança como sujeito de 
direitos e ator social, a BNCC (2017, p. 34) define a Educação Infantil como "a primeira etapa da educação básica; é o início e o fundamento do processo educacional (...)”, revelando uma concepção de criança enquanto produtora de cultura e construtora do seu conhecimento.

As DCNEI (2009, p. 12) definem currículo como "conjunto de práticas que buscam articular as experiências e os saberes das crianças com os conhecimentos que fazem parte do patrimônio cultural (...) de modo a promover o desenvolvimento integral de crianças (...)". Definem, também, que as práticas pedagógicas que compõem a proposta curricular da EI devem ter como eixos norteadores as interações e a brincadeira, de modo que o brincar, além de se constituir como um direito da criança torna-se o meio pelo qual todas as propostas devem se organizar.

Numa perspectiva de currículo mais prescritiva, a BNCC (2017, p. 5), “é um documento de caráter normativo que define o conjunto orgânico e progressivo de aprendizagens essenciais que todos os alunos devem desenvolver ao longo das etapas e modalidades da educação básica (...)".

É possível observar uma priorização das práticas cotidianas pelas DCNEI e uma priorização dos objetivos de aprendizagem e desenvolvimento pela BNCC.

A defesa de um currículo prescritivo para a EI busca se antagonizar a ideia da falta de equidade das oportunidades educacionais oferecidas em diferentes regiões do país que poderia causar defasagens de aprendizagem e às políticas de avaliação em larga escala, que acabam por prescrever esse currículo a partir da forma e do conteúdo das avaliações.

Cabe ressaltar que a produção desses documentos é influenciada por fatores internacionais, nacionais e locais. A sua intenção é induzir propostas e práticas cotidianas na EI. No entanto, eles chegam às escolas e aos professores de forma dinâmica e não linear, pois passam por diversas reinterpretações, fruto do contexto histórico e das questões (sociais, culturais, econômicas, educacionais) nacionais e locais. Deste modo, os professores influenciam e são influenciados pelo seu contexto discursivo, pelas suas marcas culturais e pelas suas relações sociais.

Esses documentos curriculares, carregados de descrições e/ou prescrições, buscam superar, discursivamente, outras possíveis significações, com a intenção de ditar, de forma totalizadora, a forma como as crianças brasileiras devem ser educadas, seja no âmbito da política curricular nacional, seja no âmbito dos ritos pedagógicos cotidianos, aqueles que acontecem "dentro dos muros da escola". No entanto, é impossível que possam, de fato, fazêlo.

Essa impossibilidade está expressa na abundância de significações e sentidos que podem ser percebidos para além daqueles que estão expressos nos documentos. Tal impossibilidade revela, também, a ambivalência presente nos documentos, cujos sentidos expressos deslizam entre currículo enquanto prática e currículo enquanto prescrição. Esse deslizamento acaba por enaltecer, na EI, uma "falta" em relação ao EF, de uma maior intencionalidade e sistematização de suas práticas.

Compreendemos esse jogo de disputas discursivas a partir da noção da não existência de fundamentos ou determinações que permitam a fixação de sentidos de forma permanente, pois esta é fruto de disputas, articulações e interpretações sempre precárias e contingentes. 
Essa indeterminação e precariedade é o que permite novas articulações, disputas e significações e possibilita que, "dentro dos muros da escola", a EI continue buscando as suas significações, experimentando e consolidando práticas e ritos pedagógicos cotidianos que possam, de fato, ter a criança e seus processos de desenvolvimento e aprendizagem como centro.

\section{O professor da/na El na rede pública municipal do Rio de Janeiro}

Historicamente voltada para os filhos das classes média e alta, a pré-escola consolidouse como um espaço-tempo voltado para o desenvolvimento de habilidades e percepções que contribuísse para a aprendizagem/alfabetização futura, enquanto a creche atendia prioritariamente as crianças oriundas das classes trabalhadoras (CAMPOS, 2006). Concebida como um "vir a ser", a criança, nesta etapa, era pouco considerada em seu momento atual e nas suas potencialidades de inserção e produção cultural.

Diante deste quadro, (OLIVEIRA 2013, p.13) defende que "a formação dos profissionais que atuam na Educação Infantil apresenta-se como o mais urgente e polêmico dos desafios a serem enfrentados". Tal desafio, segundo a autora, se apresenta diante da multiplicidade de arranjos informais que, durante décadas, vigorou no atendimento à EI, principalmente no segmento creche. Impera, ainda, a necessidade iminente de se conceber as especificidades de cuidado e educação necessárias à EI, cujos modelos de formação do professor que vigoraram durante muito tempo, voltadas às outras etapas de ensino, não deram (e ainda não dão) conta.

Urgente também, segundo a autora, é "superar a separação que, historicamente, marcou o atendimento à criança pequena no Brasil entre, por um lado, a creche, concebida como espaço de cuidados, e, por outro, a pré-escola, vista como espaço de educação e de preparação para o Ensino Fundamental" Oliveira (2013, p.9). Tal separação pode ser observada nas práticas comuns ainda encontradas atualmente, de organização das rotinas do segmento creche a partir de ações de higiene, alimentação e sono e do segmento pré-escola a partir da realização de atividades de percepção e treinamento viso-motor, entre outras consideradas necessárias ao bom aprendizado futuro.

Kramer (2006) aponta que formar professores para lidar com criança pequena é tarefa nova na história da escola brasileira. Estando a EI até o final da década de 1980 à margem dos sistemas educacionais, a atuação dos profissionais deste segmento estava mais estreitamente atrelada às ações de cuidado, mais próximas às condições domésticas, sem a exigência de uma formação específica para a atuação docente. No município do Rio de Janeiro, por exemplo, quando municipalizadas, as creches eram vinculadas à Secretaria Municipal de Desenvolvimento Social - SMDS/RJ.

Sendo assim, mesmo nas redes públicas oficiais, (OLIVEIRA, 2013, p.5) denuncia que "neste segmento está concentrado o maior número de professores com a remuneração mais baixa e que cumprem as mais extensas jornadas de trabalho".

$\mathrm{Na}$ busca por atender ao postulado no artigo 62 da LDB 9394/96, que exige a formação em nível superior para os professores da EB, incluindo, nesta, a EI, observamos uma grande 
expansão na oferta de formação nas modalidades presencial e a distância. Sonia Kramer (2006) aponta que o ingresso nas redes municipais do professor de Educação Infantil se dá, comumente, como professor de Ensino Fundamental.

O que se observa, segundo Sonia Kramer (2006) é uma "lacuna" na formação inicial dos professores que ingressam no magistério, uma vez que nem a Universidade, nem o Curso Normal, dão conta dessa tarefa em todas as suas nuances e necessidades. Cabe, então, às redes de ensino, assumirem parte desse desafio em formação continuada para os professores e demais profissionais que atuam na EI.

Diante da necessidade de as redes públicas se adequarem aos novos padrões de qualidade educacional, expressos, principalmente, na necessidade de elevação dos índices de aproveitamento nas avaliações externas, observamos uma crescente preocupação dessas redes em propiciar diferentes oportunidades de aperfeiçoamento profissional aos professores que já estão atuando.

Destacamos que, quando nos referimos à EI, atualmente, estamos nos referindo aos segmentos creche e pré-escola. No entanto, a EI e nesta, a creche, foi incorporada muito recentemente à EB. A pré-escola tem um atendimento consolidado há mais tempo, pois a "educação da criança de 4 a 6 anos insere-se nas ações do Ministério da Educação (MEC) desde 1975, quando foi criada a Coordenação de Educação Pré-Escolar.” (BRASIL, 2006, p. 7). Antes disso, algumas redes municipais (do Rio de Janeiro, por exemplo) e privadas já incorporavam a pré-escola às suas redes de ensino. Sendo assim, a formação de professores para este segmento, ainda que não se configurassem como uma exigência para a atuação do professor, era contemplada por algumas modalidades de formação, como os Estudos Adicionais ${ }^{1}$ e habilitações oferecidas pelo curso de Pedagogia em algumas universidades.

Na rede municipal do Rio de Janeiro essa situação não era diferente: os professores e gestores que atuavam na EI, seja na modalidade creche ou na modalidade pré-escola, eram oriundos do EF (Professor II - PII). Essa situação mudou com a criação do cargo de Professor de Educação Infantil (PEI) e a realização do primeiro concurso para provimento neste cargo em 2011. No entanto, esses profissionais foram, inicialmente, lotados, prioritariamente, nas creches e nos $\mathrm{EDI}^{2}$, pois estes ainda não contavam com professores atuando diretamente nas turmas. Dessa forma, as turmas de pré-escola continuaram sendo atendidas, em sua grande maioria, por professores oriundos do EF. Atualmente, há grande quantidade de PEI atuando na pré-escola, juntamente com os PII.

Posteriormente, no ano de 2019 foi criado o cargo de Professor Adjunto da Educação Infantil (PAEI), para que, gradativamente, substituam os Agentes de Educação Infantil (AEI), de modo que toda essa etapa seja atendida por profissionais que possuam, no mínimo, a formação de professores em nível médio, na modalidade Normal.

A necessidade de formação continuada para esses professores, tanto os que atuam na creche quanto os que atuam na pré-escola é iminente. Porém, o que se observa na rede pública municipal do Rio de Janeiro é que ela acontece, prioritariamente, por meio de publicações destinadas a orientar o trabalho do professor em sala de aula. Entre as publicações mais expressivas, enumeramos as seguintes: Orientações Curriculares para a Educação Infantil (2010); Orientações aos Profissionais da Educação Infantil (2010); Caderno de Planejamento 
da Educação Infantil (2011); Orientações ao Professor de Pré-escola I e II (2013); Orientações para a organização da sala na Educação Infantil: ambiente para a criança criar, mexer, interagir e aprender (2013); Caderno de Avaliação na Educação Infantil (2013); Currículo Carioca (2020). Tais publicações têm como princípio a orientação de normas e procedimentos que "devem" ser adotados pelos professores e demais profissionais que atuam na Educação Infantil, assumindo, dessa forma, o papel de "formadores" desses profissionais.

\section{Caminhos e descaminhos... buscando ressignificar a política}

Segundo a TD (LACLAU e MOUFFE, 2014) não existem fundamentos ou determinações que permitem a fixação de sentidos de forma permanente. No entanto, é possível compreender, no jogo de disputas discursivas, as articulações que permitem que alguns elementos do currículo da EI sejam significados, ainda que precariamente. A indeterminação das significações é o que permite que novas disputas e novas articulações busquem novas significações, sempre contingentes, o que não significa que outros sentidos e outras significações sejam suplantados.

As escolas da rede pública municipal do Rio de Janeiro que atendem à etapa da EI permaneceram sem atendimento presencial às crianças desde o dia 16/03/2020, voltando a reabrir de forma gradual e escalonada no dia 24/02/2021, num modelo de atendimento que compreende propostas remotas síncronas e/ou assíncronas e atendimento presencial para grupos reduzidos de crianças. Os professores e as equipes gestoras das unidades escolares foram incentivados a propor encontros remotos com as famílias, de forma a manter os vínculos afetivos durante o período de fechamento.

A SME/RJ produziu, neste período, cadernos pedagógicos destinados aos grupamentos de maternal II (crianças de três anos) e pré-escola (crianças de quatro e cinco anos), com o objetivo de subsidiar escolas e professores no atendimento remoto às crianças.

Cabe ressaltar que a produção de material didático para crianças da pré-escola já era uma política curricular adotada pela SME/RJ desde o ano de 2010, tendo sido interrompida no período de 2017 a 2019. Já para o segmento creche, essa produção teve início no período de pandemia e chegou às crianças e famílias apenas no formato virtual. Tais cadernos seguiam a proposta dos anteriores e constituíam-se de atividades de "cunho alfabetizador", priorizando "conteúdos" ligados à alfabetização e à matemática, reforçando, desse modo a concepção de Educação Infantil como uma etapa preparatória.

No início de 2021, uma nova gestão assumiu a SME/RJ, com o desafio de organizar o atendimento a todas as crianças, ainda que de forma remota e trouxe a proposta de ampliação da política dos cadernos para todas as crianças da EI, incluindo os berçários, uma vez que, impresso, seria o único material que teria a sua chegada "garantida" às casas das crianças, pois não se poderia contar com o acesso de todas as famílias aos formatos virtuais. Esse foi, pois, o primeiro desafio dessa nova produção: um caderno pedagógico que seria utilizado pelas crianças no ambiente doméstico, tendo os familiares como parceiros. 
No entanto, essa nova especificidade de uso desse material mostrou-se como a própria possibilidade de reinterpretação da política. $\mathrm{O}$ desafio se converteu na oportunidade de fazer uma escolha dentre dois caminhos possíveis: manter a produção nos mesmos moldes dos anteriores ou conceber um material que se organizasse a partir de novas concepções de infância e de aprendizagem, com uma nova apresentação gráfica e novas propostas, ainda que no mesmo suporte, de caderno pedagógico.

Ao decidir pela segunda opção, destacamos alguns apontamentos que ajudaram a desenhar o formato do novo caderno: a compreensão da escola e da família como instâncias parceiras na promoção do desenvolvimento e da aprendizagem da criança; o entendimento de que a organização e as práticas escolares não podem ser "transportadas" para a casa das crianças no período de afastamento da escola; a percepção de que as crianças já estavam sendo submetidas a um confinamento domiciliar e a um distanciamento social que lhes cerceavam a movimentação ampla e que já estavam demasiado expostas a conteúdos audiovisuais, entre outras. Sendo assim, essas crianças não poderiam ser ainda mais aprisionadas!

O Currículo Carioca, documento curricular municipal, embora assuma um caráter prescritivo, organizado em torno de objetivos de aprendizagem por faixa etária, é passível de diferentes interpretações, o que permitiu a proposição de um material que sugere diferentes vivências e experiências com materiais facilmente encontrados no ambiente doméstico, sem conter "atividades alfabetizadoras".

Nesta perspectiva, neste ano de 2021, os cadernos assumiram algumas características bem distintas dos anteriores: se organizaram a partir de experiências a serem vivenciadas pelas crianças no ambiente domiciliar com o corpo, com materiais cotidianos, com a literatura, com o desenho, com a água, com o som, com elementos da natureza, entre outras; trouxeram textos literários e brincadeiras que valorizam a cultura e os valores africanos e indígenas e deram visibilidade às crianças e escolas da rede pública municipal, por meio de registros fotográficos que ilustram as propostas contidas nos cadernos.

No material destinado ao segmento creche, não há espaço para "escritas" diretas das crianças, pois ele se organiza em torno de propostas de brincadeiras e jogos a serem realizados em famílias; no material destinado à pré-escola, são poucos os espaços para "escritas" das crianças e essas priorizam o registro, por diferentes meios, das experiências vivenciadas. Desse modo, estes cadernos compreendem os Campos de Experiência como núcleos integradores das propostas a serem vivenciadas, e consideram as interações e a brincadeira como a própria linguagem e a forma como a criança se coloca no mundo.

É sabido que um dos principais objetivos do uso de materiais estruturados na EI é o de influenciar a docência, seja pelo planejamento das práticas, seja pela determinação dos conteúdos de ensino que acabam por determinar, de alguma forma, as práticas cotidianas. Essa foi, claramente, uma das propostas desse novo material: influenciar os professores para que, ao planejarem os encontros remotos com as crianças, priorizassem a brincadeira, a interação, as experiências com diferentes materiais, afastando-se de práticas mecanizadas e preparatórias, principalmente no contexto da pandemia, buscando fixar um conceito de EI vinculado à ampliação das experiências da criança, ainda que no ambiente doméstico. 
No entanto, esse não é o único conceito de EI que emerge no contexto atual. Cabe ressaltar que neste ano de 2021 estamos vivenciando, também, um momento de decisão política no que tange à adesão, ou não, dos municípios ao Programa Nacional do Livro e do Material Didático - PNLD, que visa distribuir sistemas apostilados para uso pelas crianças da pré-escola em todo o Brasil. Esse material, segundo Edital de Convocação no 02/2020 do Fundo Nacional de Desenvolvimento da Educação - FNDE deve estar de acordo com a Política Nacional de Alfabetização - PNA (Decreto no 9.765 de 11 de abril de 2019). Esta se trata de um documento orientador, ou seja, que não tem a força de lei, mas que pretende definir a forma como se dará a alfabetização em âmbito nacional, defendendo uma única concepção de alfabetização, de abordagem fonética, baseada na Ciência Cognitiva da Leitura.

O município do Rio de Janeiro optou por não fazer a adesão ao PNLD, o que consideramos uma importante decisão que corrobora para a valorização dos currículos locais e da produção autoral dos materiais didáticos. Esta opção exemplifica que, mesmo num momento no qual as políticas curriculares apontem para a prescrição e a unificação de concepções e práticas, é possível encontrar brechas para buscar estabelecer significações diversas.

\section{Considerações finais}

Compreendemos que os cadernos pedagógicos para a EI apresentam-se como uma política curricular carregada de prescrições e de controle do trabalho docente e dos processos de aprendizagem das crianças, que tem sido amplamente adotada em muitas redes públicas e privadas do país. No entanto, nesta experiência relatada, abriu-se espaço para a fixação de outra compreensão e de outra utilização desse material, ainda que provisória, uma vez que a significação do currículo e do próprio material didático para a EI continuam sendo disputadas.

Optar pela mudança de perspectiva é ter a compreensão da provisoriedade e da imprevisibilidade das decisões políticas, o que não exclui a necessidade de que decisões sejam tomadas. Decidir, sem a garantia da eficácia da decisão tomada, pode ser compreendido como uma potência, como um lançar-se a novas possibilidades de interpretações das políticas. Um material que não tem a pretensão de trazer sentidos absolutos pode possibilitar que professores e crianças ressignifiquem a sua experiência com/na EI.

\section{Notas:}

1. Ao final do curso normal, por opção, o professor podia complementar por mais um ano, o chamado quarto normal, também chamado de Estudos Adicionais, em uma área específica, que o habilitava a atuar até a $6^{\text {a }}$ série (atual $7^{\circ}$ ano) ou educação infantil. Foi uma medida adotada na época dos anos 1970 até o início da 
década seguinte, para sanar a falta de professores. As áreas específicas eram: Estudos Sociais, que habilitava para o ensino de História e Geografia, Ciências, Matemáticas e Educação Infantil.

2. EDI - Espaços de Desenvolvimento Infantil. Unidade Escolar que abrange somente os segmentos creche e/ou pré-escola.

\section{Referências}

BRASIL, Ministério da Educação. Secretaria de Educação Básica. Política nacional de Educação Infantil: pelo direito das crianças de zero a seis anos à educação. Brasília: DF BRASIL. Lei no 9394, 20 de dezembro de 1996. Estabelece as Diretrizes e Bases da Educação Nacional. BRASIL. Brasília: DF, 1996.

BRASIL, Ministério da Educação. Secretaria de Educação Básica. Política nacional de Educação Infantil: pelo direito das crianças de zero a seis anos à educação. Brasília: DF, MEC, SEB, 2006.

BRASIL. Base Nacional Comum Curricular: A educação é a base. MEC, SEB. Brasília: DF, 2017.

BRASIL. Decreto no 9.765, de 11 de abril de 2019. Institui a Política Nacional de Alfabetização. Brasília: DF, 2019.

BRASIL. Ministério da Educação. Conselho Nacional de Educação. Resolução CNE/CP $\mathbf{n}^{0}$ 5de 17 de dezembro de 2009. Fixa as Diretrizes Curriculares Nacionais para a Educação Infantil. Brasília: CNE, 2009.

BRASIL. Ministério da Educação. Conselho Nacional de Educação. Resolução CNE/CP no 5 de 17 de dezembro de 2009. Fixa as Diretrizes Curriculares Nacionais para a Educação Infantil. Brasília: CNE, 2009.

CAMPOS, Maria Malta. Educação Infantil: conquistas e desafios. In: SANTOS, Emerson (org.) Reescrevendo a Educação: propostas para um Brasil Melhor. Rio de Janeiro, Ática, 2006. p. 91-104.

KISHIMOTO, Tizuko Morchida. Política de formação profissional para a Educação Infantil: Pedagogia e Normal Superior. Educação \& Sociedade, ano XX, nº 68, Dezembro/1999, p. 61-79.

KRAMER, Sonia. A criança de 0 a 6 anos nas políticas educacionais no Brasil: Educação Infantil e/é fundamental. Educação e Sociedade, Campinas, v. 27, no 96 - Especial pág. 797-818, out. 2006.

LACLAU, Ernesto; MOUFFE, Chantal. Hegemonia e estratégia socialista. Por uma política democrática radical. São Paulo: Intermeio, 2014.

NASCIMENTO, Maria L. B. P. As políticas públicas de Educação Infantil e a utilização de sistemas apostilados no cotidiano de creches e pré-escolas. Revista Brasileira de Educação, v. 17 n. 49 jan-abr. 2012 p. 59-80.

OLIVEIRA, Dalila Andrade. Profissão docente na Educação Infantil. In: Salto para o futuro. Ano XXIII Boletim 10 - Junho 2013.

RIO DE JANEIRO (Prefeitura) A avaliação na Educação Infantil. Rio de Janeiro: RJ, 2013.

RIO DE JANEIRO (Prefeitura) Caderno de planejamento da Educação Infantil. Rio de Janeiro: RJ, 2011.

RIO DE JANEIRO (Prefeitura) Currículo Carioca. Rio de Janeiro: RJ, 2020.

RIO DE JANEIRO (Prefeitura) Orientações ao professor de pré-escola I e II. Rio de Janeiro: RJ, 2013.

RIO DE JANEIRO (Prefeitura) Orientações aos profissionais da Educação Infantil. Rio de Janeiro: RJ, 2010.

RIO DE JANEIRO (Prefeitura) Orientações curriculares para a Educação Infantil. Rio de Janeiro: RJ, 2010.

RIO DE JANEIRO (Prefeitura) Orientações para a organização da sala na Educação Infantil: ambiente para a criança criar, mexer, interagir e aprender Rio de Janeiro: RJ, 2013. 


\section{Correspondência}

Cátia Cirlene G Oliveira: Doutora em Educação pelo PROPED - UERJ na Linha "Currículo, Sujeitos, Conhecimento e Cultura". Atuou como professora de alfabetização de adultos na SEE - RJ (1990-1999); como professora regente, gestora e coordenadora pedagógica em unidades de educação infantil da SME - RJ; como professora-tutora presencial do curso de pedagogia na modalidade a distância pelo Consórcio Cederj (2005-2013) e como professora-formadora do PNAIC (2013-2015) Atualmente é Professor II da Prefeitura da Cidade do Rio de Janeiro, atuando na Educação Infantil da Secretaria Municipal de Educação. Pesquisadora no grupo de pesquisa "Políticas de Currículo e Docência", PROPED-UERJ.

E-mail: ccirlenego@gmail.com

Texto publicado em Currículo sem Fronteiras com autorização dos autores. 